\title{
Kliniğimizde Son 18 Aylık Tubaovaryan Apse Tedavisinde Laparoskopi Deneyimlerimiz
}

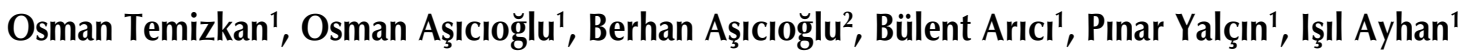

\begin{abstract}
ÖZET:
Kliniğimizde son 18 aylık tubaovaryan apse tedavisinde laparoskopi deneyimlerimiz

Amaç: Çalışmada primer amacımız tubaovaryan apse tanılı hastalarda apse boyutunun klinik ve laboratuar sonuclarına etkisi ve cerrahi tedavide laparoskopi yönteminin etki ve güvenililirliğini değerlendirmek.

Gereç ve Yöntem: Kliniğimizde son 18 aylık dönemdeki tubaovaryan apse (TOA) tanısıyla medikal tedaviye yanıt vermeyen 42 adet laparoskopi yapılan hasta retrospektif incelendi.

Bulgular: Yapılan değerlendirmede hastaların ortalama yaşı 38.7 olarak belirlendi. Bu hastaların \%16.6'sı menopoz sonrası dönemde iken, \%14.2'sinde RíA mevcuttu. Ayrıca apse boyutu $7 \mathrm{~cm}$ üzerinde olan grupta 38 derece ustu ateşli hasta oranı, C-reaktif protein (CRP), eritrosit sedimentasyon hızı (ESH) ve lökosit sayısı anlamlı olarak yüksek bulundu. Yapılan 42 laparoskopi operasyonunda sadece 1 hastada termal ureter hasarı oldu ve ikincil operasyon hiçbir hastaya gerekmedi.

Sonuç: Yeterli cerrahi tecrübe olan kliniklerde TOA cerrahi tedavisinde laparoskopi oldukça güvenli ve etkili bir tedavi olarak görünmektedir.
\end{abstract}

Anahtar kelimeler: Tubaovaryan apse, laparoskopi, CRP, eritrosit sedimentasyon hızı

\section{ABSTRACT:}

Last 18 months experience of laparascopic tuboovarian abcess treatment in our clinics

Objective: Our primary objective in this study was to evaluate whether the size of the abscess affects clinical or laboratory results; also to evaluate efficacy and safety of laparascopy in surgical treatment.

Material and Method: 42 patients diagnosed as having tuboovarian abscess (TOA) who did not respond to medical treatment and underwent laparascopic surgery in last 18 monhts in our clinic were retrospectively analysed.

Results: Mean age of patients was 38.7 years. $16.6 \%$ of those were postmenopausal and $14.2 \%$ had intrauterine device. Fever above 38 degrees celcius, c-reactive protein (CRP), erithrocyte sedimentation rate, leukocyte count were significantly higher in the group of patients who had abscesses over 7 centimeters. Only one patient had thermal urether injury, none needed secondary operation.

Conclusion: Laparascopy is a very efficient and safe way in surgical treatment of tuboovarian abscess in surgically-experienced centers

Key words: Tuboovarian abscess, laparascopy, CRP, erithrocyte sedimetation rate

Ş.E.E.A.H. Tıp Bülteni 2015;49(3):181-6
'Şişli Hamidiye Etfal Eğitim ve Araştırma Hastanesi, Kadın Doğum Kliniği,

İstanbul-Türkiye

${ }^{2}$ GOP Taksim Eğitim Araştırma Hastanesi, Kadın Doğum Kliniği, İstanbul-Türkiye

Yazışma Adresi / Address reprint requests to: Osman Aşıcıoğlu,

Şişli Hamidiye Etfal Eğitim ve Araştırma Hastanesi, Kadın Doğum Kliniği, İstanbulTürkiye

E-posta / E-mail:

oasicioglu@yahoo.com.tr

Geliş tarihi / Date of receipt: 16 Ocak 2015 / January 16, 2015

Kabul tarihi / Date of acceptance: 3 Mart 2015 / March 3, 2015

\section{GíRiş}

Tubaovaryan apse (TOA) tuba, over yada etraf dokuların enfeksiyonlarının ilerlemiş son halidir. TOA genellikle pelvik enflamatuar hastalıktan (PEH) özellikle premenopozal hastalarda gelişir. Hematojen yada lenfatik yayılımlarda TOA gelişimine neden olabilir (1). TOA sezeryan, histerektomi ve tüp ligasyonu gibi bazı jinekolojik ve obstetrik operasyonlarında sonucu olabilir (1). Amerika Birleşik Devletle- 
rinde verilere göre $\mathrm{PEH}$ nedenli yatan hastaların yaklaşık \%20-30 kadarının altın TOA olduğu bildirilmiştir (2-4). Bu oran Avrupa ve Türkiye içinde benzerdir $(5,6)$. TOA gelişiminde belli başlı risk faktörleri içinde: İmmunsupresyon, rahim içi araç kullanımı, PEH hikayesi, adölesan çağda olmak sayılabilir. TOA gelişiminde aerob, anaerob ve fakültatif mikroorganizmaların beraber enfeksiyonudur. Vakaların yarısından çoğunda anaerop bakteriler izole edilmekle beraber en sık izole edilen bakteriler: Escherichia coli, Bacteroides şuşları (özellikle Bacteroides fragilis), Peptostreptokok şuşları, Peptokok şuşları ve Aerop Streptokok şuşlarıdır $(7,8)$.

Apse tedavisi günümüzdede tartışmalıdır. Başlangıç tedavi intravenöz antibiyotik tedavisini takiben oral antibiyotiktir. Eğer medikal tedavi başarısız olursa sonraki aşama laparoskopik yada laparatomik olarak apse drenajı, adneksektomi yada histerektomidir. Bir diğer yaklaşımda görüntü eşliğinde kateterle iğne aspirasyonu ve antibiyotik tedavisi olabilir (1). Ancak son zamanlarda özellikle genç hastalarda koruyucu cerrahininde öneminden dolayı laparoskopi altın standart tedavi haline gelmiştir (9).

Bu çalışmadaki birincil amacımız kliniğimizde özellikle son zamanlarda tubaovaryan apsenin cerrahi tedavisinde rutin kullandığımız laparoskopik cerrahi tedavinin güvenliliğini ve etkisini değerlendirmektir.

\section{GEREÇ VE YÖNTEM}

Bu retrospektif çalışma hastanemiz Kadın Hastalıkları ve Doğum Kliniğinde 01 Temmuz 2013 ile 01 Aralık 2014 tarihleri arasında yürütülmüştür. Hastanemiz İstanbul'un batısında tersiyer refere bir merkez olma özelliği taşımaktadır. Çalışma için hastane etik kurul raporu alınmış ve değerlendirilen 42 hastadan yazılı onam alınmıştır. Çalışma 2008 Helsinki bildirgesine uygun olarak gerçekleştirilmiştir.

TOA tanısı PEH bulguları; abdominal ağrı ve vajinal muayenede servikal yada adneksiyel hassasiyet vede 1 yada daha fazla minör kriter (38 derece üstü ateş, 10.000/ml üstü lökosit ve eritrosit sedimentasyon hızı (ESH) $15 \mathrm{~mm} / \mathrm{h}$ üstü) ve ultrasonda kitle imajı (düzensiz kenarlı, eko veren, peristaltizm göster- meyen) görülmesiyle konmuştur $(1,10)$. Eğer ultrason muayenesi ile kesin tanıya varılamamışsa bilgisayarlı tomografi yada manyetik rezonans ile tanı kesinleştirilmiştir.

Başvuruda öncelikle tüm hastaların yaş, kilo, boy, menopozal durum, kondom kullanımı, pelvik cerrahi hikayesi, şeker hastalığı ve rahim içi araç (RIA) varlığı sorgulanıp not edildi. Daha sonra tam kan sayımı, ESH, C-reaktif protein (CRP) düzeyi bakıldı. Hastalarda RiA varsa tedavi başladıktan 48-72 saat sonra çıkarıldı.

Bu süre içinde TOA tanısıyla toplam 99 hastaya yatış yapıldı başlangıç tedavisi klindamisin ile gentamisin yada seftriakson ile metronidazol oldu. Hastalara enaz 4 gün antibiyotik tedavisi verildi. Klinik düzelip vucut ısısı normal hale geldikten 48 saat sonrası dönemde intravenöz tedaviden oral tedaviye geçildi. Oral tedavide de 14 gün boyunca günde 2 kez 100 mg doksisiklin verildi.

Tedavi başarısızlığı antibiyotik tedavisine rağmen 72 saat ateşin devamı yada 48 saat peritoneal bulguların devamı olarak kabul edildi ve bu hastalara laparoskopi ile cerrahi tedavi uygulandı (apse drenajı, tek yada iki taraflı salpenjektomi yada salfingooferektomi, total yada subtotal histerektomi). Tedavi sonunda tüm hastaların görüntüleme bulguları, antibiyotik tedavi çeşiti, komplikasyonlar ve hastanede kalış süreleri not edildi.

İstatistiksel yöntemlerde SPSS 20.0 programı kullanıldı. Kategorik değişkenler için kikare testi kullanıldı. Normal dağılımlı değişkenlerde t test kullanıldı. Normal olmayan dağılımlı değişkenlerde MannWhithey $U$ testi kullanıldı. P değeri 0.05 altında ise istatiksiksel anlamlı olarak kabul edildi.

\section{BULGULAR}

Çalışmamızda hastanemize TOA tanısıyla yatırılıp antibiyotik tedavinin başarısız olup cerrahi yolla tedavi edilen 42 hasta incelendi. Hastaların karakteristikleri Tablo 1'de özetlenmiştir. Hastaların yaş ortalaması $38.7 \pm 11.7$ olarak bulundu. Apse ortalama boyutu ise $6.8 \pm 1.8 \mathrm{~cm}$ olarak bulundu. Hastaların 19 tanesi 40 yaş üzeri olarak belirlendi. Ayrıca $7 \mathrm{~cm}$ üzeri apse boyutu olan hasta sayısı 18 (\%42.8) olarak bulundu. Ayrıca hastaların 7 (\%16.6) tanesi postme- 
Tablo 1: Klinik ve demografik özellikler

\begin{tabular}{|c|c|}
\hline Özellikler & Değer \\
\hline Yaş (yıl) & $38.7 \pm 11.7$ \\
\hline VKi $\left(\mathrm{kg} / \mathrm{m}^{2}\right)$ & $27.9 \pm 1.1$ \\
\hline Sigara & $16(38)$ \\
\hline Alkol & $6(14.2)$ \\
\hline Gravida & $3.4 \pm 1.0$ \\
\hline Parite & $2.7 \pm 1.0$ \\
\hline Menopoz & $7(16.6)$ \\
\hline Diabetes Mellitus & $3(7.1)$ \\
\hline RiA & $6(14.2)$ \\
\hline Pelvik cerrahi öyküsü & $18(42.8)$ \\
\hline Kondom kullanımı & $19(45.2)$ \\
\hline Apse boyutu (cm) & $6.8 \pm 1.8$ \\
\hline Apse boyutu $7 \mathrm{~cm}$ & $18(42.8)$ \\
\hline \multicolumn{2}{|l|}{ TOA yeri } \\
\hline Sağ adneks & $19(45.2)$ \\
\hline Sol adneks & $17(40.4)$ \\
\hline Bilateral & $6(14.2)$ \\
\hline CRP (mg/l) & $22.4 \pm 7.7$ \\
\hline $\mathrm{ESH}(\mathrm{mm} / \mathrm{h})$ & $53.6 \pm 18.3$ \\
\hline WBC sayısı & $17005 \pm 2415$ \\
\hline Ateş $\geq 38$ derece & $13(30.9)$ \\
\hline \multicolumn{2}{|l|}{ Antibiyotik tedavi rejimi } \\
\hline Klindamisin+gentamisin & $30(71.4)$ \\
\hline Seftriakson+metronidazol & $12(28.5)$ \\
\hline Hastanede kalış (gün) & $9.2 \pm 1.8$ \\
\hline
\end{tabular}

Tablo 2: Laparoskopik yapılan operasyonlar ve komplikasyonlar

\begin{tabular}{lc}
\hline Özellikler & Değer \\
\hline Cerrahi tipi & \\
Sadece drenaj & $8(19.0)$ \\
Drenaj+ USO yada BSO & $13(30.9)$ \\
Drenaj+ Salpenjektomi & $20(47.6)$ \\
Drenaj+ Histerektomi & $1(2.3)$ \\
Komplikasyon & \\
Mesane zedelenmesi & 0 \\
Barsak zedelenmesi & 0 \\
Üreter zedelenmesi & $1(2.3)$ \\
\hline
\end{tabular}

Tüm değerler: sayı (\%) olarak verilmiştir. USO: tek taraflı salfingooferektomi, BSO: iki taraflı salfingooferektomi

nopozal dönemde ve 3 (\%7.1) tanesi diabetik olarak belirlendi (Tablo 1).

Tüm hastalara laparaskopi yöntemi uygulandı ve aynı ekip tarafından cerrahi gerçekleştirildi (O.A., O.T., B.A.). Hiçbir hastada laparoskopi sonrasi laparatomiye dönülmedi. Hastaların tümüne apse drenajı uygulandı 34 (\%81) tanesine ek işlem olarak salpenjektomi, salpingooferektomi yada histerektomi işlemi uygulandı. Cerrahi komplikasyon olarak sadece 1 hastada ureterde termal hasar gerçekleşti ve postope- ratif dönemde hastaya uretereskopi ile "Double J" katater takılarak tedavi edildi (Tablo 2).

Hastalar apse boyutuna göre $7 \mathrm{~cm}$ baz alınarak 2 bölüme ayrıldı. Hastaların \%42.8'i 7 cm üzerinde apseye sahipti. Her iki grubun demografik özellikleri birbirine benzer bulundu, ancak apse boyutu $7 \mathrm{~cm}$ üzeri olan grupta laboratuar bulgularından CRP düzeyi, ESH ve lokosit sayıları anlamlı olarak yüksek bulundu(tüm değerler için $p$ değeri $<0.001)$. Ayrıca takip sırasında 38 derece üstü ateşi olan hasta sayısı $7 \mathrm{~cm}$ üzeri apse boyutu olan grupta anlamlı olarak fazla bulundu [9(\%50) vs 4(\%16.7), p değeri:0.021]. Hastanede kalış ve cerrahi komplikasyon oranıda her iki grupta benzer olarak bulundu (Tablo 3).

Son olarak hastalar 40 yaş altı ve üstü olarak 2 gruba ayrıldı ve her 2 grubun klinik ve cerrahi sonuçları birbirine benzer bulundu (Tablo 4).

\section{TARTIŞMA}

Bu retrospektif çalışma bize antibiyotik tedavisine cevap vermeyen TOA hastalarında cerrahide laparoskopik yöntemin gerekli cerrahi deneyimi olan merkezlerde oldukça güvenli bir tedavi metodu olduğunu gösterdi.

TOA özellikle 3. ve 4. dekadlardaki kadınlarda sık görülmekle beraber çocukluk dönemi ve postmenopozal dönemde daha nadir görülmektedir (1). Çalışmamızdada hastaların \%16.6 kısmı postmenopozal olup hastalarımızın yaş ortalaması bizim çalışmamızda da 38 olarak bulundu. TOA jinekoloji kliniklerinde tanı anından optimal tedavisinin seçimine kadar tüm aşamalarda hekime zorluk ve sıkıntı yaşatan bir klinik durumdur. Varras ve ark. (10) ultrason bulgularının TOA için spesifik olmadığını, ayrıca CRP, ESH ve lokosit artışının ultrasonda adneksiyal alanda dopplerde kan akımının artması ile transvajinal ultrason ve vajinal muayenede servikal ve abdominal hassasiyetin tanı için önemli olduğunu belirtmiştir. Bizde kliniğimizde tanı için bu sıkı kriterleri kullanıp, ultrason bulguları yeterli olmassa tomografi yada manyetik rezonans ile tanıya gitmeye çalıştık. Ayrıca Paik ve ark. (11) jinekoloji kliniklerine TOA nedeniyle yatışın zamanla arttığını ve bu durumun gitgide önemli bir sorun olduğunu çalışmalarında belirtmişlerdir. Bizde kliniğimizde TOA nedeniyle 
Tablo 3: Tuboovaryen abse boyutuna göre klinik ve labaratuar bulgu karşılaştırılması

\begin{tabular}{|c|c|c|c|c|}
\hline Özellikler & $\begin{array}{c}\text { TOA }<7 \mathrm{~cm} \\
(\mathrm{n}: 24)\end{array}$ & $\begin{array}{c}\text { TOA } \geq 7 \mathrm{~cm} \\
(\mathrm{n}: 18)\end{array}$ & p değeri & $\begin{array}{c}\text { Relatif Risk } \\
\text { (\%95 güven aralığı) }\end{array}$ \\
\hline Yaş (yıl) & $38.5 \pm 10.9$ & $39.1 \pm 12.8$ & 0,869 & --- \\
\hline VKi $(\mathrm{kg} / \mathrm{m} 2)$ & $27.9 \pm 1.2$ & $27.8 \pm 1.0$ & 0,940 & --- \\
\hline Sigara & $9(37.5)$ & $7(38.6)$ & 0.927 & $0.9(0.4-2.0)$ \\
\hline Alkol & $3(12.5)$ & $3(16.7)$ & 0.703 & $0.7(0.1-3.2)$ \\
\hline Gravida & $3.3 \pm 0.9$ & $3.5 \pm 1.1$ & 0.500 & --- \\
\hline Parite & $2.6 \pm 08$ & $3.0 \pm 1.3$ & 0.277 & --- \\
\hline Menopoz & $3(12.5)$ & $4(22.2)$ & 0.403 & $0.5(0.1-2.2)$ \\
\hline Diabetes Mellitus & $2(8.3)$ & $1(5.6)$ & 0.729 & $1.5(0.1-15.0)$ \\
\hline RiA & $3(12.5)$ & $3(16.7)$ & 0.703 & $0.7(0.1-3.2)$ \\
\hline Pelvik cerrahi öyküsü & $10(41.7)$ & $8(44.4)$ & 0.857 & $0.9(0.4-1.8)$ \\
\hline Kondom kullanımı & $11(45.8)$ & $8(44.4)$ & 0.929 & $1.0(0.5-2.0)$ \\
\hline TOA yeri & & & 0.591 & --- \\
\hline Sağ adneks & $10(41.7)$ & $9(50)$ & & \\
\hline Sol adneks & $10(41.7)$ & $7(38.8)$ & & \\
\hline Bilateral & $3(12.5)$ & $3(16.7)$ & & \\
\hline $\mathrm{CRP}(\mathrm{mg} / \mathrm{l})$ & $17.8 \pm 4.2$ & $28.6 \pm 7.0$ & $<0.001$ & --- \\
\hline $\mathrm{ESH}(\mathrm{mm} / \mathrm{h})$ & $43.0 \pm 14.6$ & $67.8 \pm 12.0$ & $<0.001$ & --- \\
\hline WBC sayısı & $16300 \pm 3000$ & $17900 \pm 1650$ & $<0.001$ & --- \\
\hline Ateş $\geq 38$ derece & $4(16.7)$ & $9(50)$ & 0.021 & $0.3(0.1-0.9)$ \\
\hline \multicolumn{5}{|l|}{ Antibiyotik tedavi rejimi } \\
\hline Klindamisin+gentamisin & $16(66.7)$ & $14(77.8)$ & 0.430 & $0.8(0.5-1.2)$ \\
\hline Seftriakson+metronidazol & $8(33.3)$ & $4(22.2)$ & & \\
\hline Hastanede kalış (gün) & $9.2 \pm 2.0$ & $9.4 \pm 1.5$ & 0.631 & --- \\
\hline Cerrahi komplikasyon & $\mathrm{O}(0)$ & $1(5.6)$ & 0.243 & --- \\
\hline
\end{tabular}

Değerler; değerıstandart sapma ve sayı (\%) olarak verilmiştir. VKi: vücut kitle indeksi, RiA: rahim içi araç, TOA: tubaovaryan apse, CRP: C-reaktif protein, ESH: eritrosit sedimentasyon hızı, WBC: lokosit sayısı

Tablo 4: Yaşa göre klinik ve cerrahi sonuçları

\begin{tabular}{|c|c|c|c|c|}
\hline Özellik & $\begin{array}{c}\text { yaş<40 } \\
(n: 23)\end{array}$ & $\begin{array}{c}y a s ̧ \geq 40 \\
(n: 19)\end{array}$ & p değeri & $\begin{array}{c}\text { Relatif Risk } \\
\text { (\%95 güven aralığı) }\end{array}$ \\
\hline Diabetes mellitus & $1(4.3)$ & $2(10.5)$ & 0.439 & $0.4(0.01-4.2)$ \\
\hline \multicolumn{5}{|l|}{ Antibiyotik rejimi } \\
\hline cli+genta & $16(69.6)$ & $14(73.7)$ & 0.769 & $0.9(0.6-1.3)$ \\
\hline sef+met & $7(30.4)$ & $5(26.3)$ & & \\
\hline Ateş $\geq 38$ derece & $7(30.4)$ & $6(31.6)$ & 0.936 & $0.9(0.3-2.3)$ \\
\hline Cerrahi komplikasyon & $0(0)$ & $1(5.6)$ & 0.265 & --- \\
\hline Hastanede kalış & $9.4 \pm 1.9$ & $9.0 \pm 1.6$ & 0.459 & --- \\
\hline
\end{tabular}

Değerler; değer土standart sapma ve sayı (\%) olarak verilmiştir. Cli+genta: Klindamisin+gentamisin, sef+met: seftriakson+metronidazol

yatan hasta sayısının zamanla arttı̆̆ını gözlemledik ve bu durumun hastanemizin İstanbul'da refere bir merkez olmasına ve zamanla PEH neden olan bulaşıCı hastalıkların zamanla artmasına bağlıyoruz. Risk faktörlerine baktığımız zaman çok eşlilik, geçirilmiş jinekolojik operasyonlar ve RiA sayılabilir. Ginsburg ve ark.' ları RIA oranını \%48 oranında bulmuş olsalarda biz çalışmamızda RiA hasta oranını \%18 bulduk. $\mathrm{Bu}$ bulgu sadece cerrahi yapılan hastaların incelenmesine ve Türkiye'de bayanların korunmada RiA yöntemini tercih etmemesine bağlanabilir.
Tanı konduktan sonra tedavi de hala tartışılan bir konu olmakla beraber genellikle ilk aşamada geniş spektrumlu intravenöz antibiyotik kullanılmaktadır, daha sonra oral tedaviye geçilip 14 gün tedaviye devam edilmesi önerilir. Daha önce yapılan çalışmalarda Sweet ve ark. (12) tedaviye cevap oranı olarak \%70 oranı verirken, ülkemizde çok merkezli çalışmamızda oran \%74 olarak bulunmuştur (6). Bu çalışmamızda ise kliniğimizde cevap oranı \%60 civarında bulundu. Biz bunun nedenini ise TOA neden olan bakterilerin zamanla antibiyotiklere karşı direnç 
geliştirebilmesine bağlamaktayız. Apsenin boyutu da antibiyotik tedavisinde önemli olmakla beraber boyut arttıkça cerrahiye gereksinimde artmaktadır. Reed ve ark. (13) apse boyutu $10 \mathrm{~cm}$ üstü ise cerrahi \%70 buna karşın $5 \mathrm{~cm}$ altındaysa \%20 gerektiğini bildirmişlerdir. Çalışmamızda apse çapının ortalama $7 \mathrm{~cm}$ olması da cerrahi oranının yüksekliğine neden olabilir. Apse boyutu cerrahiye gereksinim oranına etki ettiği gibi birçok laboratuar sonuçlarını da etkileyebilmektedir. Bizde çalışmamızda apse boyutu büyük olan hastalarda CRP, ESH, 38 derece üstü ateş oranının ve lökosit sayısının anlamlı derecede fazla olduğunu bulduk. Bu bulgularımız daha önce yapılan ve Halperin ve ark. (14) tarafından yayınlan çalışmaya benzerdi. Bu bulgulara dayanarak apse boyutunun hastaların klinik, laboratuar bulguları ve cerrahiye gereksinimde etkili olduğunu söyleyebiliriz.

Cerrahi tedavi gereksinimi olduğu anda hangi yöntemin güvenli ve etkili olduğu hala çok tartışmalı ve ciddi bir konudur. Ancak TOA kliniğinin üreme çağındaki bayanlarda sık görülen bir durum olmasından dolayı en az invaziv ve konservatif yöntemin seçilmesi çok mantıklıdır. Çünkü Kaplan ve ark. (15) laparatomi yapılan hastalarda \%8'lere varan oranda barsak hasarı bildirmişlerdir. Bu nedenle son yıllarda görüntü eşliğinde abse drenajı ve laparaskopi yöntemleri ön plana çıkmaktadır. Ancak görüntü eşliğinde drenaj işlemi de başarısızlığa ve sonrasında cerrahi tedavi gereksinimine neden olabilir ki Gjellan ve ark. (16) \%5 oranında apse drenajı sonrası cerrahi gereksinim bildirmişlerdir. Serimizde laparoskopi yöntemi ile tedavi edilen hastaların hiçbirinde barsak hasarı ile karşılaşılmadı aynı zamanda hiçbir hasta tekrar opere edilmedi. Ayrıca cerrahi yapılan hastalar için hastanede kalış süresine baktığımızda biz ortalama 9 günlük bir süre bulduk ki bu bulgu daha önceki çalışmalara göre oldukça makul bir süredir $(6,17)$. Şen ve ark. (17) cerrahi yapılan grupta süreyi 16 gün gibi vermişlerdir ki biz bu sonucu tüm operasyonların laparoskopi ile yapılmasına bağlıyoruz. Artık günümüzde TOA apse cerrahi tedavisinde hasta konforu, komplikasyonların azlığı, etkinliğinin yüksek olması ve minimal invaziv olması nedeniyle laparoskopi altın standart olmaya başlamıştır (18). Bizde klinik olarak bu görüşü benimsemekte ve rutin olarak TOA tedavisinde laparoskopik cerrahi yöntemi kullanmaktayız ve bulgularımız laparoskopinin güvenli ve etkinliği konusunda bize destek olmaktadır.

Cerrahi yöntemin seçilmesi kadar yapılan ameliyatın tipide önemlidir. Bizim serimizde sadece drenaj $\% 19^{\prime}$ unda yapıldı. En sık salpenjektomi \%47 ve tek yada iki taraflı salpingooferektomi \%30 yapıldı. Histerektomi sadece 1 hastaya yapıldı ki, bu bulgu apsenin geliştiği hastaların genellikle üreme çağındaki hastalar olmasından dolayı oldukça makul görülmektedir.

Sonuç olarak yaptığımız retrospektif çalışmada cerrahi gereken hastalarda apse boyutunun klinik ve laboratuar bulgulara etki ettiğini, hasta yaşının kliniği ve cerrahi sonuçları çok etkilemediğini ve en önemli olarak cerrahi gereksinimde laparoskopik yöntemin güvenli ve etkin bir yöntem olduğunu bu nedenle cerrahi tecrübenin olduğu merkezlerde laparoskopik tedavinin en iyi ve geçerli yöntemlerden biri gibi olduğu kanısına vardık.

\section{KAYNAKLAR}

1. Chappell CA, Wiesenfeld HC. Pathogenesis, diagnosis, and management of severe pelvic inflammatory disease and tuboovarian abscess. Clin Obstet Gynecol 2012; 55: 893-903.

2. McNeeley SG, Hendrix SL, Mazzoni MM, Kmak DC, Ransom SB. Medically sound, cost-effective treatment for pelvic inflammatory disease and tuboovarian abscess. Am J Obstet Gynecol 1998; 178: 1272-8.

3. Franklin LW, Hevron JE, Thompson. "Management of the pelvic abscess". Clin Obstet Gynecol 1973; 16: 66-79.

4. Ginsburg DS, Stern JL, Hamod KA, Genadry R, Spence MR.Tuboovarian abscess: a retrospective review. Am J Obstet Gynecol 1980; 138: 1055-58.

5. Granberg S, Gjelland K, Ekerhovd E. Best practice and research. Best Pract Res Clin Obstet Gynecol 2009; 23: 667-78.

6. Güngördük K, Guzel E, Asicioğlu O, Yildirim G, Ataser G, Ark C. et al. Experience of tubo-ovarian abscess in western Turkey. Int J Gynaecol Obstet 2014; 124: 45-50.

7. Wiesenfeld HC, Sweet RL. Progress in the management of tuboovarian abscesses. Clin Obstet Gynecol 1993; 36: 433-44.

8. Landers DV, Sweet RL. Tubo-ovarian abscess: contemporary approach to management. Rev Infect Dis 1983; 5: 876-84.

9. Porpora MG, Gomel V. The role of laparoscopy in the management of pelvic pain in women of reproductive age. Fertil Steril 1997; 68: 765-79.

10. Varras M, Polyzos D, Perouli E, Noti P, Pantazis I, Akrivis Ch. Tubo-ovarian abscesses: spectrum of sonographic findings with surgical and pathological correlations. Clin Exp Obstet Gynecol 2003; 30: 117-21. 
11. Paik Ck, Waetjen LE, Xing G, Dai J, Sweet RI. Hospitalizations for pelvic inflamatory disease and tuboovarian abscess. Obstet Gynecol 2006; 107: 611-6.

12. Sweet RL, Schachter J, LandersDV,Ohm-SmithM, RobbieMO. Treatment of hospitalized patients with acute pelvic inflammatory disease: comparison of cefotetan plus doxycycline and cefoxitin plus doxycycline. Am J Obstet Gynecol 1988; 158: 736-41.

13. Reed SD, Landers DV, Sweet RL. Antibiotic treatment of tuboovarian abscess: comparison of broad-spectrum beta-lactam agents versus clindamycin-containing regimens. Am J Obstet Gynecol 1991; 164: 1556-62.

14. Halperin $R$, Svirsky $R$, Vaknin Z, Ben-Ami I, Schneider D, Pansky M. Predictors of tuboovarian abscess in acute pelvic inflammatory disease. J Reprod Med 2008; 53: 40-4.
15. Kaplan AL, Jacobs WM, Ehresman JB. Agressive management of pelvic abscess. Am J Obstet Gynecol 1967; 98: 482-87.

16. Gjelland K, Ekerhovd E \& Granberg S. Transvaginal ultrasoundguided aspiration for treatment of tubo-ovarian abscess: a study of 302 cases. Am J Obstet Gynecol 2005; 193: 1323-30.

17. Sen S, Kuru O, Saygılı H, Berkman S. Tubaovaryan apsenin klinik yönetimi. ist. Tıp Fak. Dergisi 2012; 75: 19-21.

18. Buchweitz O, Malik E, Kressin P, Meyhoefer-Malik A, Diedrich K. Laparoscopic management of tubo-ovarian abscesses: retrospective analysis of 60 cases. Surg Endosc 2000; 14: 948-50. 